Research Article

\title{
Experimental Analysis of Failure Mechanisms in Masonry-PFRP Profiles Connections
}

\author{
Francesca Sciarretta ${ }^{D}$, Salvatore Russo ${ }^{D}$, and Carlo Casalegno \\ Department of Design and Planning in Complex Environments, IUAV University of Venice, Dorsoduro 2206, 30123 Venice, Italy \\ Correspondence should be addressed to Francesca Sciarretta; scifra@iuav.it
}

Received 17 April 2018; Accepted 27 August 2018; Published 21 October 2018

Academic Editor: Venu G. M. Annamdas

Copyright ( 2018 Francesca Sciarretta et al. This is an open access article distributed under the Creative Commons Attribution License, which permits unrestricted use, distribution, and reproduction in any medium, provided the original work is properly cited.

\begin{abstract}
Fibre-reinforced polymer (FRP) profiles, with their low density, high durability, and ease of construction, are particularly suitable for the retrofit of traditional masonry structures, particularly historic constructions in seismic zones. However, a critical aspect of this new technology application is the connection between FRP profiles and masonry walls. So far, no research studies are available on this subject. The authors carried out a preliminary experimental campaign on different connection systems between masonry and pultruded glass-fibre-reinforced polymer (GFRP) profiles. The note presents the immediate results of this study, focusing on the performance and collapse mechanisms; the study may contribute to the development of an effective connection system between masonry and FRP profiles to be adopted in the retrofitting of existing building with juxtaposed FRP frames.
\end{abstract}

\section{Introduction}

The rehabilitation of traditional masonry buildings deserves the greatest attention in earthquake sensitive regions and brings on a high demand for advanced materials and techniques. Currently, steel frames are frequently employed as retrofitting works to increase the global strength of brickwork structures against seismic actions. They may be placed inside or beside the walls and must be connected to the floor decks [1]. This kind of solution allows committing all or part of the loads applied after the retrofitting intervention to a new structural system, which transfers the stress to the foundations autonomously [2]. However, in the perspective of sustainability, the cost and weight of steel and the need for maintenance may become critical issues. A possible solution may be the use of pultruded fibrereinforced polymer (PFRP) profiles instead of steel ones. Compared to traditional materials like wood, steel, and aluminium, FRP composites show significant advantages, mainly due to the high strength and low density (meaning lightweight structures and quick and easy construction and reduction of working cost) and the high resistance to environmental actions. The latter can give FRP composites superior durability and reduced need for maintenance, favouring a long service life and the possibility of complete cost recovery. On the other hand, the disadvantages of FRP materials lie mainly on the production cost and environmental footprint [3]. As well, we lack design codes and longterm data which can validate predictions about durability of FRP structures in real working conditions [4]; finally, FRP's brittle behavior, high shear deformability, and vulnerability to fire and ultraviolet radiation are disadvantageous aspects. Nonetheless, available studies confirm that FRP structures could achieve relevant sustainability goals; a significant example is the Aberfeldy footbridge, whose structural performance has not significantly declined 20 years after construction [5]. Sustainable construction with FRP is possible especially thanks to the immunity to electrochemical corrosion [6], meaning also superior performances in chlorine-affected environment if compared to steel [7].

Current research concerns the impact of loads and environmental factors on FRP structures' and retrofits' durability [8]. Moisture and contact with water, by damaging mainly the matrix, lead to decrease in tensile strength although effects are reversible [9]; gel-coating was developed to prevent moisture-induced damage. Long-term exposure 
to high temperatures $\left(60-70^{\circ} \mathrm{C}\right)$ can induce permanent chemical alterations leading to internal cracking and strength reduction [10], due to the proximity of glass transition temperature (e.g., $130-170^{\circ} \mathrm{C}$ for epoxy). Thermal cycles cause stress reversal which lead to superficial cracking; freeze-thaw cycles can be more dangerous, although some studies have revealed a minor or no impact on the composite's mechanical properties [11]. The creep strain induces increment in deflections of FRP pultruded beams and a significant reduction in their buckling strength [12]. On the other hand, the excellent resistance of FRP composites to fatigue phenomena under moderate cyclic loads was enlightened [13]. Finally, the dynamic behavior of pultruded FRP structures and subparts is studied especially in view of FRP composites' application to constructions in seismic zones, favoured by the low density and high strength; while seismic design codes generally do not account for the use of brittle materials, the overall concept and design of the structure can ensure the required ductility [14].

Currently, the main fields of use of FRP pultruded profiles in construction are hybrid construction systems (e.g., concrete-filled FRP tubes), hybrid concrete-FRP bridges, and all-FRP bridges and footbridges (truss, cablesupported, girder + deck, or FRP deck only). On the other hand, strengthening techniques combining pultruded FRP profiles and masonry structures have not yet been explored in theory nor in practice.

The use of pultruded FRP frame systems for the refurbishment of buildings-as a possible alternative choice to traditional steel or aluminium frames-shows great potentiality still to be fully exploited. Some remarkable case studies in Italy demonstrate the optimum choice of FRP pultruded profiles instead of steel for the strengthening of historic structures, i.e., the Paludo Bridge in the damp and salty environment of the Venice lagoon [15] and a wooden floor deck of a heritage palace in Spoleto [16]. Also, numerical simulations are helpful in understanding the feasibility and usefulness of FRP replacing steel; for instance, Casalegno and Russo [17] have pointed out that braced steel frames show higher ductility and stiffness than FRP ones, but FRP moment frames can have a similar stiffness and a higher ultimate capacity than analogous steel ones.

As the wall-frame connections are certainly a critical aspect in traditional metallic frames, this would certainly become even more important for FRP in consideration of its particular features, such as the anisotropic behavior and the sensitivity to stress concentrations that may lead to local failure. The authors are currently developing studies on adhesive connections [18]; many studies have been accounting for the analysis of connection systems between steel profiles and masonry walls $[19,20]$. Several studies have been also carried out on FRP strips mechanically fastened to concrete or wood members [21-24]. Nonetheless, no study has analyzed yet the behavior of bolted connections between PFRP profiles and masonry, and the present research is thus a first experimental investigation on this subject. Tests were carried out on different connection systems, as described in the following, in order to evaluate their performance and to analyze the collapse mechanisms. Finally, finite element (FE) analyses helped clarifying the failure behavior and strength hierarchy of the tested samples and checking the possible behavior of the connection at a larger scale. The study may contribute to the development of an effective connection system between masonry and FRP profiles to be adopted in the retrofitting of existing building with juxtaposed FRP frames.

The physical form of samples and kind of tests were motivated by previous numerical modelling, based on a global [25] and local approach [26]. The global approach, meaning the whole wall + frame system, highlighted the cracking of the masonry adjacent to rigid wall-frame connections as the first sign of damage under increasing top horizontal displacement, assuming that the connections are very rigid; the latter, because of the model's scale, is not modeled in detail (Figure 1). The detailed analysis developed thereafter accounted for a joint consisting of a FRP profile glued to a FRP plate bolted to masonry (Figure 2). The results pointed out that the principal stresses are more than ten times higher in the FRP plate than in the masonry. Nevertheless, the values of the principal stresses in the masonry in the region near to the steel bars are significantly higher than the material strength, so damage may be expected in the masonry around the bars.

\section{Materials and Methods}

The tested samples were made of a masonry block of dimensions $25 \times 25 \times 18 \mathrm{~cm}$, consisting of three layers of two bricks and general purpose lime-based mortar arranged in an English bond pattern, two $152 \times 43 \times 9.5 \mathrm{~mm}$ GFRP pultruded channel profiles and steel threaded bars. The six blocks were built directly in laboratory, with class M2.5 mortar prepared for the purpose with a ca. 23\% water volume fraction; the bricks were properly moistened just before being assembled, to avoid the development of cracking at brick-mortar interfaces while the mortar was drying. The vertical joints were filled with mortar as well. The samples were stored indoor at room temperature (i.e., $12-17^{\circ} \mathrm{C}$ ) for $28+$ days. At the same time, the pieces of the FRP profile were cut with a buzz saw, their ends were rectified with sandpaper and the necessary holes were bored; finally, the glued joints between profiles and plates for samples $1 \mathrm{a}$ and $1 \mathrm{~b}$ were made. After the curing period, the masonry specimens were perforated with a drill, and the samples were finally assembled by inserting the steel bars. This assembly simulates the junction of internal and external GFRP frame retrofits to a masonry wall. Being designed to avoid the instability of GFRP profiles, the samples underwent a vertical load up to the failure of the masonryGFRP joint. Specifically, three joint configurations were tested, i.e., six tested samples as described in Table 1 and shown in Figure 3.

Table 2 lists the material characteristics of the FRP profiles, FRP laminated plates, masonry, and epoxy adhesive. The producers provided the properties of the FRP profiles and plates, of the adhesive and of the mortar, while those of the masonry blocks were obtained from previous experimental tests carried out at the same laboratory on wallettes 


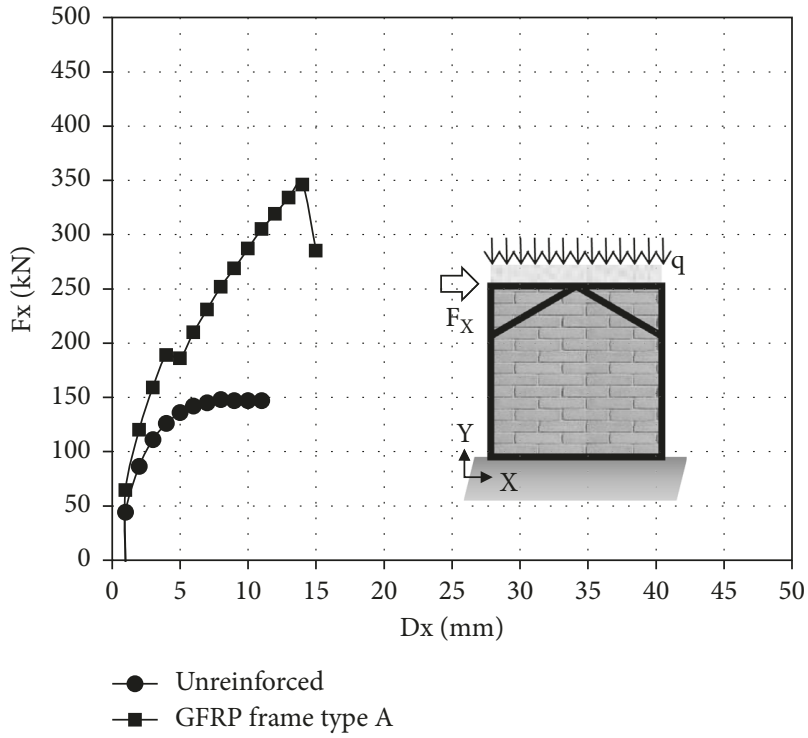

(a)

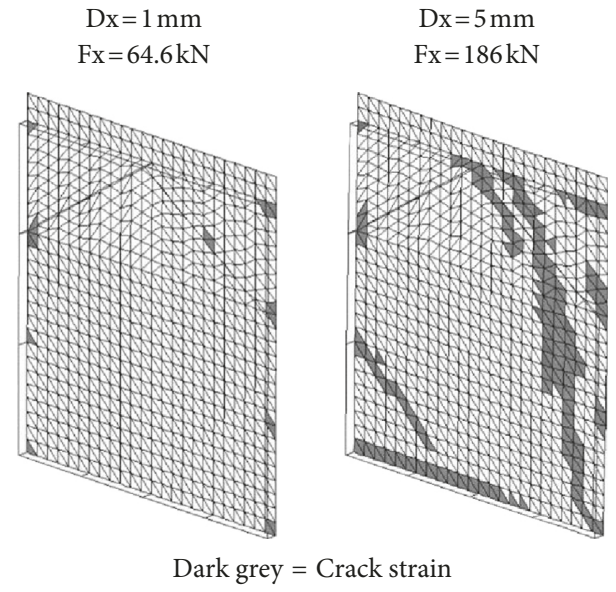

(b)

Figure 1: Output of preliminary FE global model: (a) load-displacement graph; (b) crack pattern.

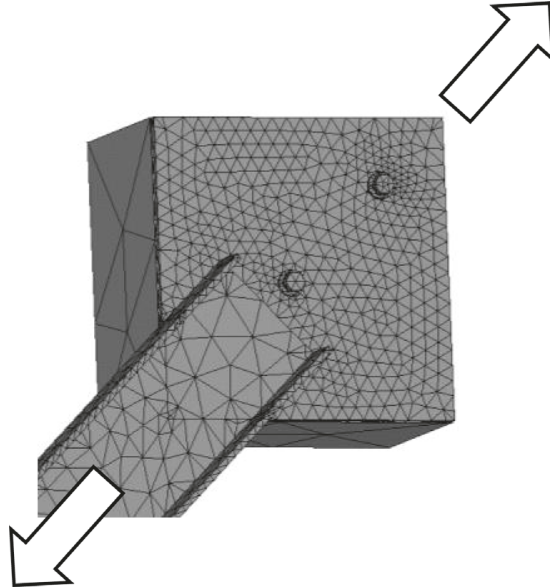

(a)

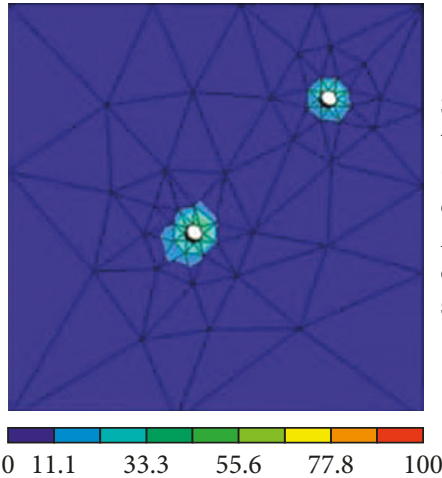

(b)

FIGURE 2: Output of preliminary finite element model: (a) model view; (b) stress intensity contour plot.

Table 1: Description of tested specimens.

\begin{tabular}{|c|c|c|}
\hline Samples' ID & Description & Reference \\
\hline $1 a, 1 b$ & $\begin{array}{l}\text { The FRP pultruded profiles are bonded to FRP } \\
\text { laminated plates by an epoxy adhesive thin layer (ca. } \\
0.5 \mathrm{~mm} \text { ). The two plates are tied together at opposite } \\
\text { sides of the masonry block by one threaded steel bar } \\
\text { passing through the block. Nuts and washers are also } \\
\text { placed to tighten the joint }\end{array}$ & Figure $3(1 \mathrm{a}, 1 \mathrm{~b})$ \\
\hline $2 a, 2 b$ & $\begin{array}{l}\text { The FRP pultruded profiles are directly connected to } \\
\text { the masonry block at opposite sides by one threaded } \\
\text { steel bar passing through the block. Nuts and washers } \\
\text { are also placed to tighten the joint }\end{array}$ & Figure $3(2 a, 2 b)$ \\
\hline $3 a, 3 b$ & $\begin{array}{l}\text { The FRP pultruded profiles are directly connected to } \\
\text { the masonry block at opposite sides by two } \\
\text { independent threaded steel bars whose length is } \\
\text { about half the thickness of the block. Nuts and } \\
\text { washers are also placed to tighten the joint }\end{array}$ & Figure $3(3 a, 3 b)$ \\
\hline
\end{tabular}




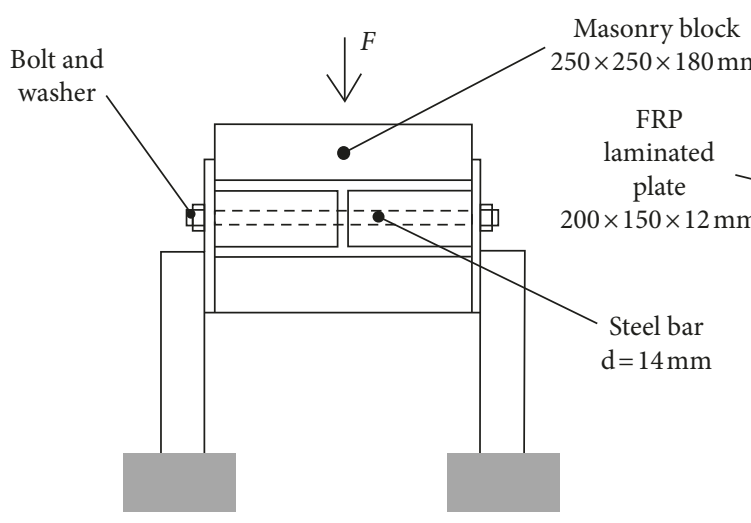

(1a)

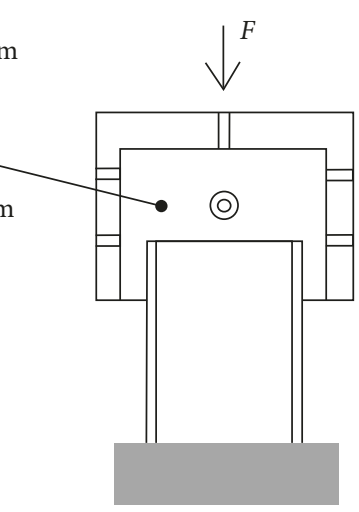

$\downarrow^{F}$

(1b)
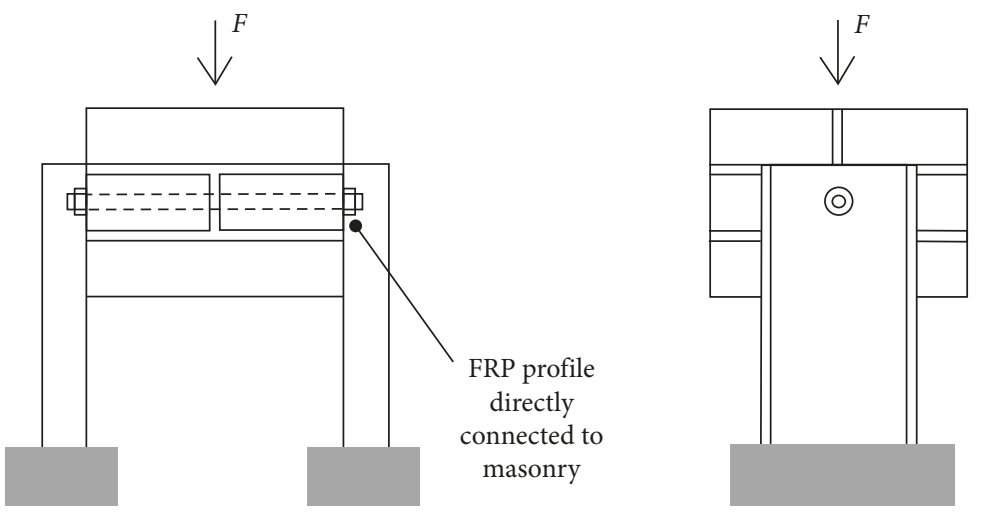

(2a)

(2b)
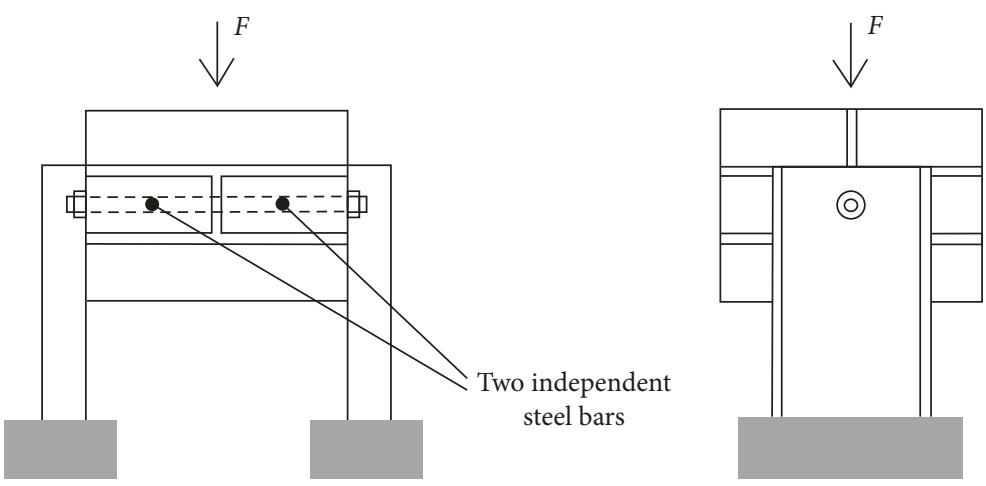

(3a)

(3b)

FIGURE 3: Different joint configurations tested.

TABLE 2: Material characteristics.

\begin{tabular}{|c|c|c|c|}
\hline Material & $\mathrm{T}\left({ }^{\circ} \mathrm{C}\right)$ & Unit & Value \\
\hline GFRP profiles & $\begin{array}{l}\text { Longitudinal compressive strength } \\
\text { Longitudinal compressive modulus of elasticity } \\
\text { Longitudinal interlaminar shear strength } \\
\text { Longitudinal shear modulus } \\
\text { Longitudinal Poisson's ratio }\end{array}$ & $\begin{array}{l}\mathrm{N} / \mathrm{mm}^{2} \\
\mathrm{~N} / \mathrm{mm}^{2} \\
\mathrm{~N} / \mathrm{mm}^{2} \\
\mathrm{~N} / \mathrm{mm}^{2} \\
-\end{array}$ & $\begin{array}{c}220 \\
18000 \\
30 \\
3000 \\
0.28 \\
\end{array}$ \\
\hline GFRP & Flexural strength & $\mathrm{N} / \mathrm{mm}^{2}$ & 150 \\
\hline Laminated plates & $\begin{array}{l}\text { Flexural modulus of elasticity } \\
\text { Compressive strength } \\
\text { Tensile strength }\end{array}$ & $\begin{array}{l}\mathrm{N} / \mathrm{mm}^{2} \\
\mathrm{~N} / \mathrm{mm}^{2} \\
\mathrm{~N} / \mathrm{mm}^{2}\end{array}$ & $\begin{array}{c}10000 \\
200 \\
90\end{array}$ \\
\hline Masonry block & $\begin{array}{c}\text { Compressive modulus of elasticity } \\
\text { Shear strength } \\
\text { Shear modulus of elasticity }\end{array}$ & $\begin{array}{l}\mathrm{N} / \mathrm{mm}^{2} \\
\mathrm{~N} / \mathrm{mm}^{2} \\
\mathrm{~N} / \mathrm{mm}^{2}\end{array}$ & $\begin{array}{l}2723 \\
0.43 \\
2540\end{array}$ \\
\hline Epoxy adhesive & $\begin{array}{l}\text { Compressive modulus of elasticity (EN 13412) } \\
\text { Bond strength-pull out test (EN 12188) } \\
\text { Compressive strength (EN 12190) }\end{array}$ & $\begin{array}{l}\mathrm{N} / \mathrm{mm}^{2} \\
\mathrm{~N} / \mathrm{mm}^{2} \\
\mathrm{~N} / \mathrm{mm}^{2}\end{array}$ & $\begin{array}{l}6000 \\
>18 \\
>70\end{array}$ \\
\hline
\end{tabular}


made of the same materials. The steel bar is made of S235 grade steel $\left(f_{y k}=235 \mathrm{~N} / \mathrm{mm}^{2}, E=210000 \mathrm{~N} / \mathrm{mm}^{2}\right)$.

The samples were put to the tests as shown by Figure 4; i.e., the stress state in the joint was induced by a vertical compressive load acting on the top face of the masonry block. The tests were performed under displacement control; the recorded values refer to the vertical displacements of the machine's upper platen, measured by the incorporated transducers. The apparel is a Dartec universal testing machine with a capacity of $1200 \mathrm{kN}$. Before the test, the specimens were applied a confinement pressure of $0.6 \mathrm{~N} / \mathrm{mm}^{2}$ by means of steel plates tightened together on the top and under the bottom surface of the block. A calculated weight put on the top plate induced the desired compressive stress in the block; then the plates were bolted to each other to keep the vertical strain of the block as it was under the pressure. This stress state is typical for brick masonry in working conditions. The confinement system is visible also in Figure 4. Rigid steel contrast plates, $4 \mathrm{~cm}$ thick, are placed between the machine and the sample. Rubber sheets $1 \mathrm{~cm}$ thick are placed between the masonry block and the confinement plates in order to guarantee a uniform distribution of the load, preventing stress concentrations that may induce local failure at the top of the masonry block or at the base of the GFRP profiles. The samples were also designed to prevent instability of the GFRP profiles.

\section{Results and Discussion}

3.1. Experimental Results. The most relevant results, i.e., the load and displacements at first and maximum peaks, are listed in Table 3. The experimental load-displacement curves relative to the different tested samples are plotted in the graph in Figure 5. The phase of settlement of the upper plate (which was very short thanks to the adopted measures for stress distribution) was subtracted from the loaddisplacement paths.

Samples 3a-b (two independent steel bars connecting the FRP profiles directly to the masonry block) gave the lowest peak load, about $9.5 \mathrm{kN}$. The flexural strain in the steel bars, which entered the plastic phase, triggered the cracking of the surrounding masonry, which was the cause of collapse. Before the highest value, sudden drops of the load were recorded due to the occurrence of vertical cracks in the masonry block (Figure 6(a)). In sample 3a, this happened for a very low applied load (Table 3 ). Both are the sign of the first development of cracking inside the masonry block around the bar. Finally, the GFRP profile showed no appreciable damage at the edge of the hole (Figure 6(b)).

Samples 2a-b (profiles connected directly to masonry with one passing-through steel bar) performed the best, reaching values of the peak load of about 30 and $19 \mathrm{kN}$, respectively, and much larger displacements than 1a-b. As for samples $3 a-b$, the flexural behavior of the bar triggered the collapse mechanism by initiating the cracks in the masonry around the plasticized steel bar.

Samples 1a-b (continuous steel bar and profiles connected to FRP plates by epoxy adhesive) reached peak loads of $13-14 \mathrm{kN}$; the collapse was characterized by a very brittle mechanism, due to the shear failure of the adhesive (Figure 7). In this case, as well, the presence of peaks revealed that the cracking of the masonry block preceded the final collapse and the GFRP profile remained undamaged.

3.2. Numerical Analysis of the Experimental Behavior. The observed experimental behavior was analyzed with nonlinear FEM analyses, to explore the collapse mode and stress distribution in a detailed way. First, a 2D model of the tested specimen was constructed, featuring the actual load and constraint conditions; then, a 3D simulation of a $116 \times 116 \times 25 \mathrm{~cm}$ wallette with and without a single-strut PFRP strengthening was set up (Figures 8 and 9). The latter analysis had the aim to clarify if the same experimental behavior could show up also at a larger scale and the possible strength increase and/or change in failure mode after the strengthening. The FEM simulations were carried out with DIANA 9.6 software; all the models were based on the same modelling scale, i.e., the masonry components were represented separately, and interfaces laid between the steel bar and the masonry as well as between the bar and the GFRP profile. The 2D models could afford a high mesh density while maintaining a very short computational time. To account for masonry cracking, the bricks and joints were given nonlinear properties according to the Thorenfeldttype curves plotted in the graph of Figure 10, representing a total strain-based cracking model. Finally, Von Mises failure criterion was adopted for steel and Hoffman plasticity (allowing for orthotropic behavior and different strength values in tension and compression) for the Pultruded FRP composite. The bar-masonry and profilemasonry interfaces, with nominal thickness of $0.5 \mathrm{~mm}$, avoided interpenetration of adjacent elements with different stiffness; they were given normal and tangential elastic stiffness proportioned to the elastic moduli of the facing materials, and the possible friction or bond-slip mechanisms were not accounted for. The $2 \mathrm{D}$ analysis accounted for the two cases without the plate, i.e., the masonry-PFRP connection with one bar and with two independent bars (abbreviated, respectively, 2a-b and 3a-b throughout the tests, as well as 1 bar and 2-bar in the FE analyses). Table 4 lists the main results of the $2 \mathrm{D}$ analyses. The maximum load is lower $(-40 \%)$ for the 2-bar model, as it happened in the experimental cases $(-63 \%)$. The models can also reproduce the experimental failure modes as shown by the graph of Figure 11 and the crack pattern plots of Figure 12. The 1-bar model undergoes bar yielding at nearly $50 \%$ of maximum load, then masonry tensile cracking below the plasticized bar at the subsequent load increment, and finally masonry crushing at the peak. In the other model, the two bars attain a little more than $50 \%$ of the yielding stress and their displacements inside the masonry block lead to concentration of damage in the central lower zone. In both models, the involvement of the GFRP profiles in the stress sharing is negligible, as it appeared to be in the tests. The main difference between the experimental graphs and numerical simulations lies in the displacement magnitude; it may be explained because the experimental displacements of 


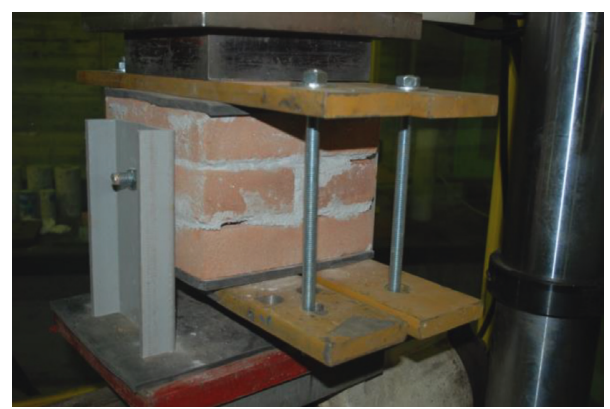

FIGURE 4: Sample 2a placed in the testing machine, before the application of the load.

TABle 3: Test results.

\begin{tabular}{lcccc}
\hline Sample & \multicolumn{2}{c}{ First peak } & \multicolumn{2}{c}{ Maximum peak } \\
Load $(\mathrm{kN})$ & Displacement $(\mathrm{mm})$ & Load $(\mathrm{kN})$ & 13.68 & 4.73 \\
\hline $1 \mathrm{a}$ & - & - & 13.36 & 4.66 \\
$1 \mathrm{~b}$ & 7.86 & 2.21 & 30.04 & 35.08 \\
$2 \mathrm{a}$ & 1.30 & 0.52 & 19.43 & 24.71 \\
$\mathrm{~b}$ & 3.76 & 1.22 & 8.85 & 3.74 \\
$3 \mathrm{a}$ & 1.37 & 0.56 & 9.34 & 9.27 \\
$3 \mathrm{~b}$ & 8.85 & 3.74 & & \\
\hline
\end{tabular}

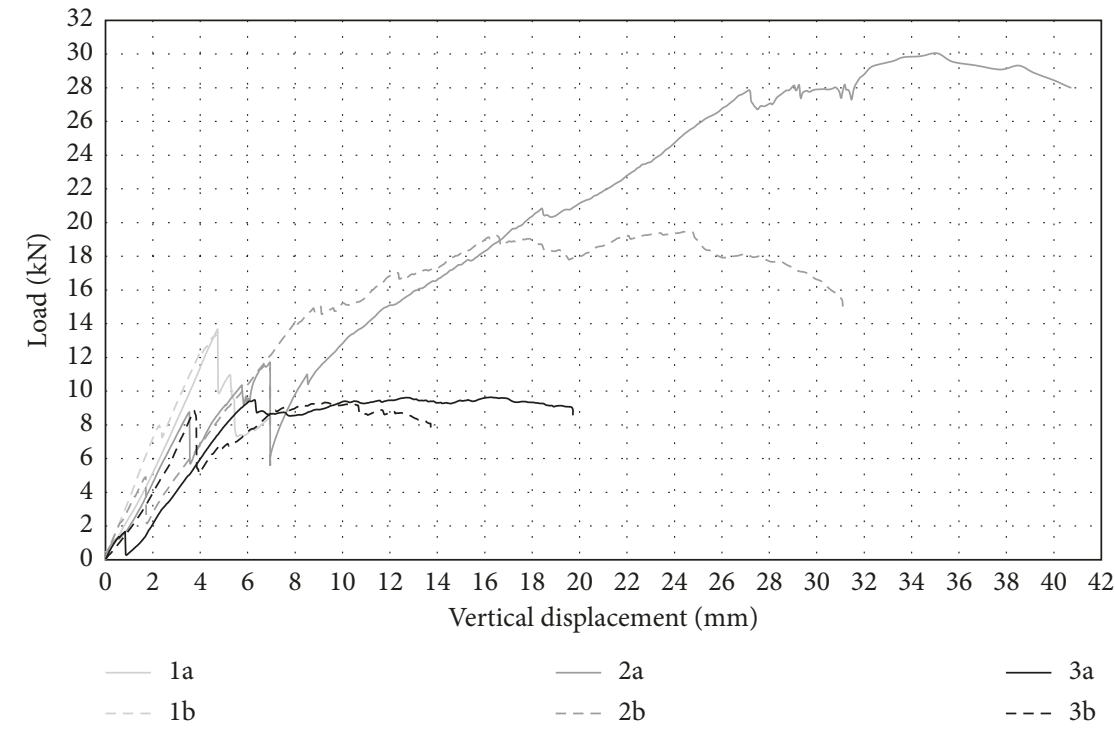

FIgURE 5: Experimental load-displacement curves.

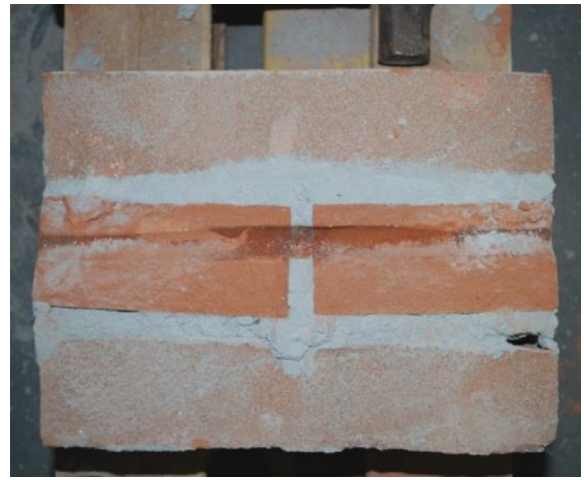

(a)

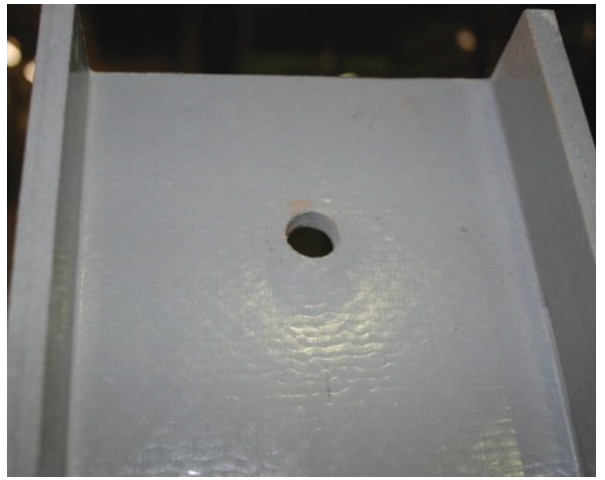

(b)

Figure 6: Collapse mechanism of samples 3a-b (a) and condition of pultruded profile after the test (b). 


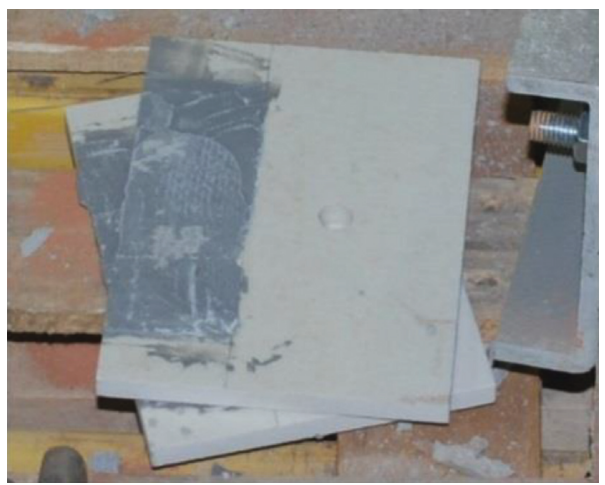

FIGURE 7: Shear failure of the adhesive in samples 1a-b.

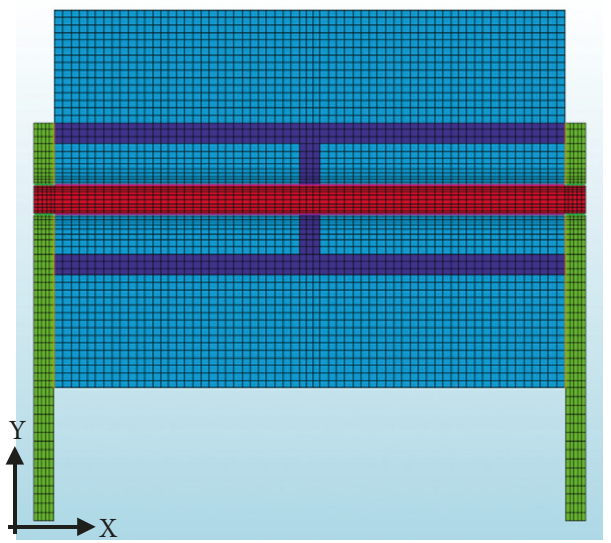

(a)

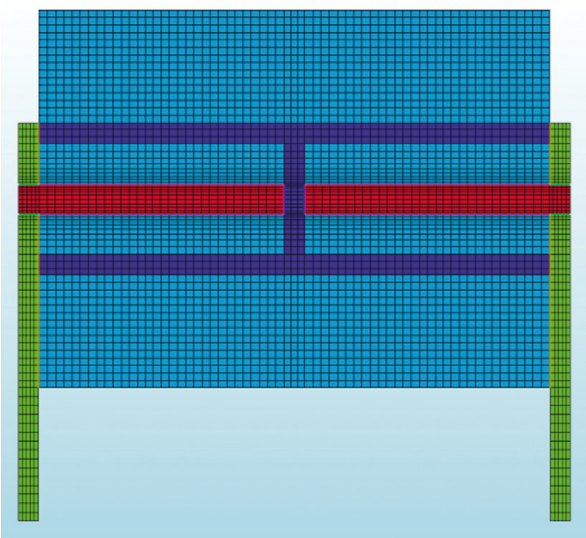

(b)

Figure 8: 2D models of the experimental specimen: (a) 1-bar and (b) 2-bar.

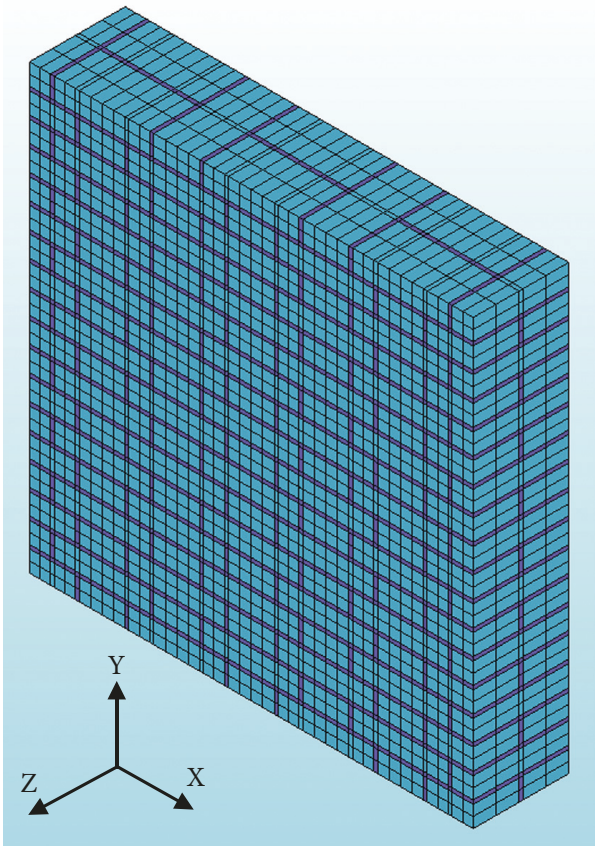

(a)

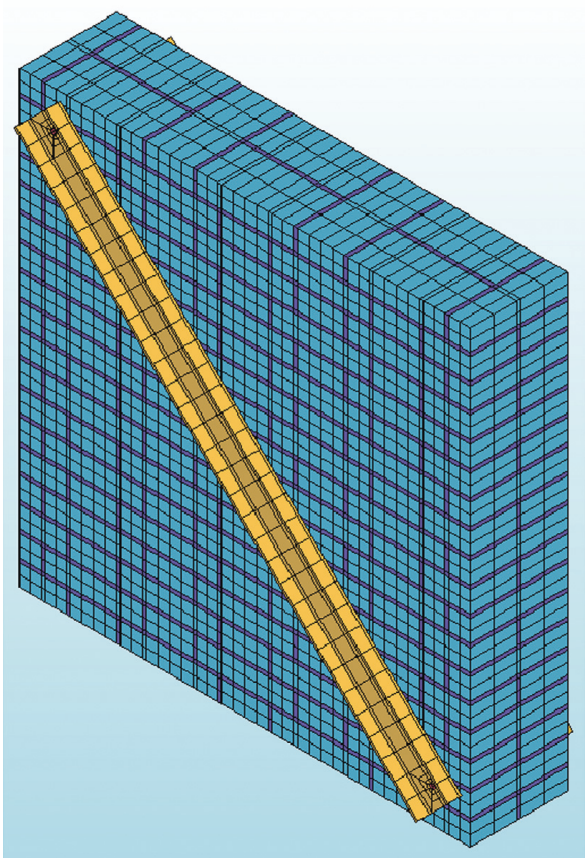

(b)

FIgURE 9: 3D models of the tested joint transposed on a $116 \times 116 \times 25$ wallette 


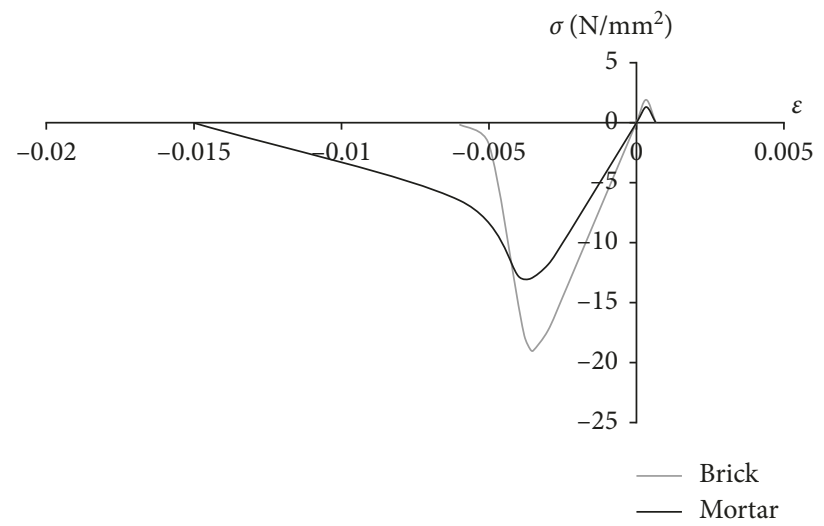

FIgURE 10: Assumed stress-strain behavior for brick and mortar.

TABLE 4: 2D FEM results.

\begin{tabular}{|c|c|c|c|c|}
\hline \multirow[b]{2}{*}{ Connection } & \multicolumn{4}{|c|}{ Values at the peak load step } \\
\hline & $\begin{array}{l}\text { Load } \\
(\mathrm{kN})\end{array}$ & $\begin{array}{l}\text { Displacement } \\
(\mathrm{mm})\end{array}$ & $\begin{array}{l}\text { Max. principal stress in the steel bar } \\
\qquad\left(\mathrm{N} / \mathrm{mm}^{2}\right)\end{array}$ & $\begin{array}{l}\text { Max. principal stress in the GFRP profile } \\
\qquad\left(\mathrm{N} / \mathrm{mm}^{2}\right)\end{array}$ \\
\hline One bar & 12.73 & 0.446 & 200 & 6.82 \\
\hline Two bars & 7.59 & 0.359 & 110 & 3.64 \\
\hline
\end{tabular}

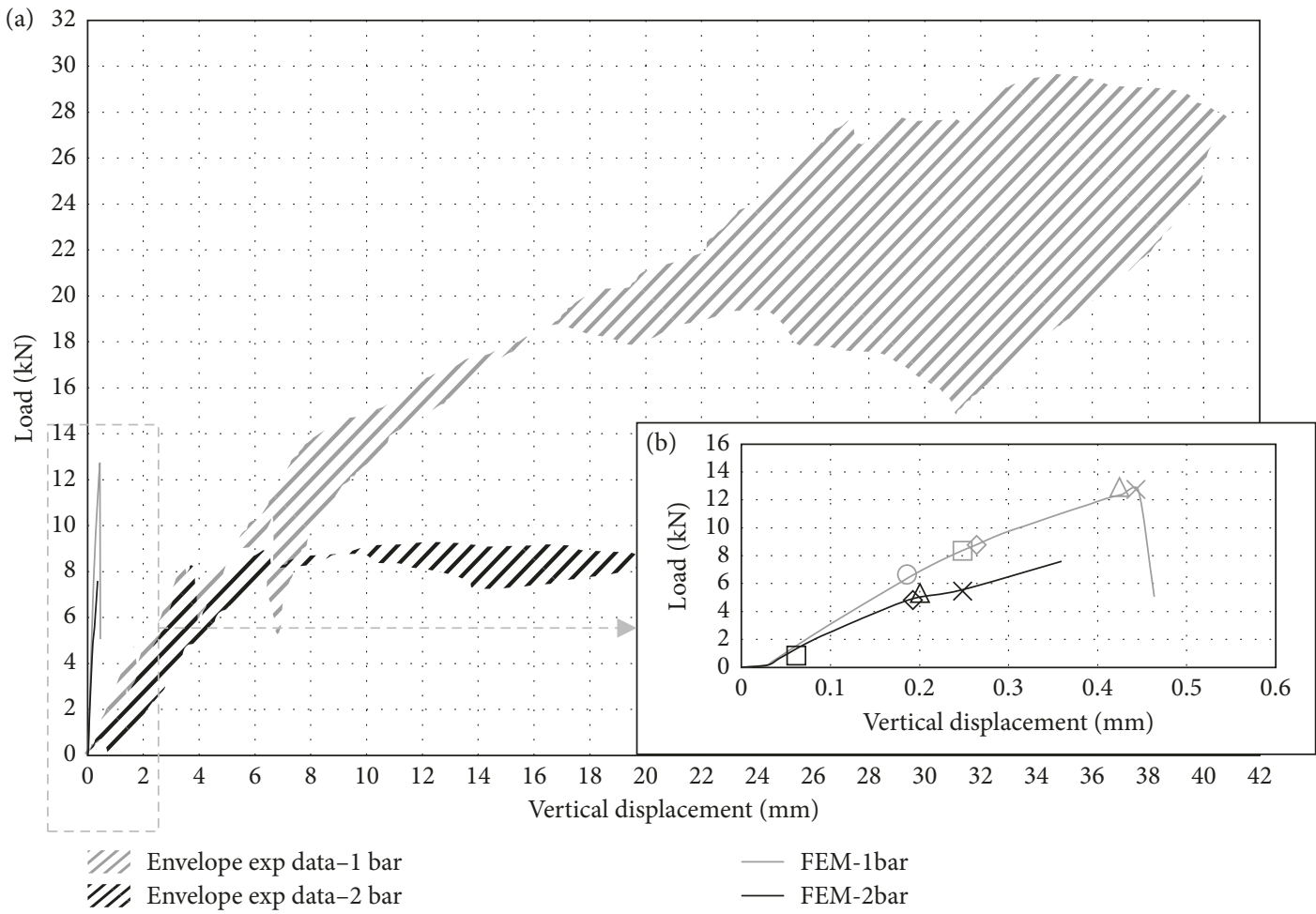

FIGURE 11: (a) Load-displacement graphs of FE analyses compared to the experimental data envelopes and (b) detailed graph of the two FE analyses, with indications of bar plasticization (circle), mortar cracking (square), brick cracking (lozenge), mortar crushing (triangle), and brick crushing (cross).

reference were those of the machine's upper platen, and manufacturing imperfections were present in the specimens.
The 3D models included the detailed reproduction of the steel bar joint with 20-node isoparametric brick elements and 8-node interfaces between the bar and the masonry 


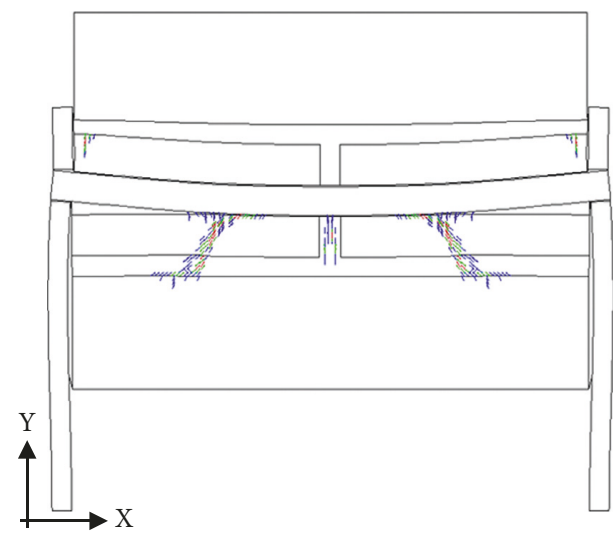

(a)

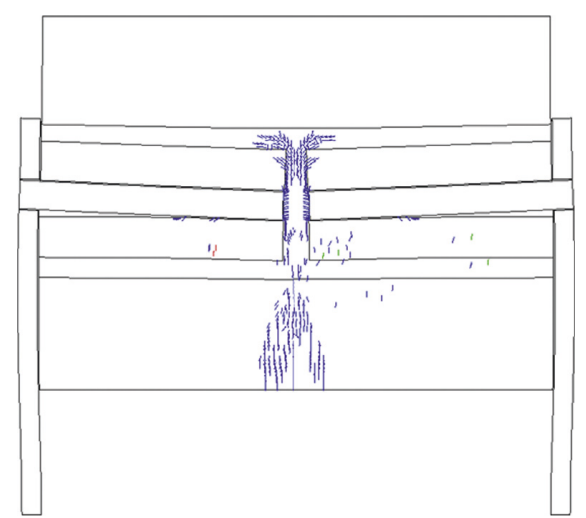

(b)

FIGURE 12: Failure crack pattern of FE models 1-bar (a) and 2-bar (b). Deformed shape factor $=20$.

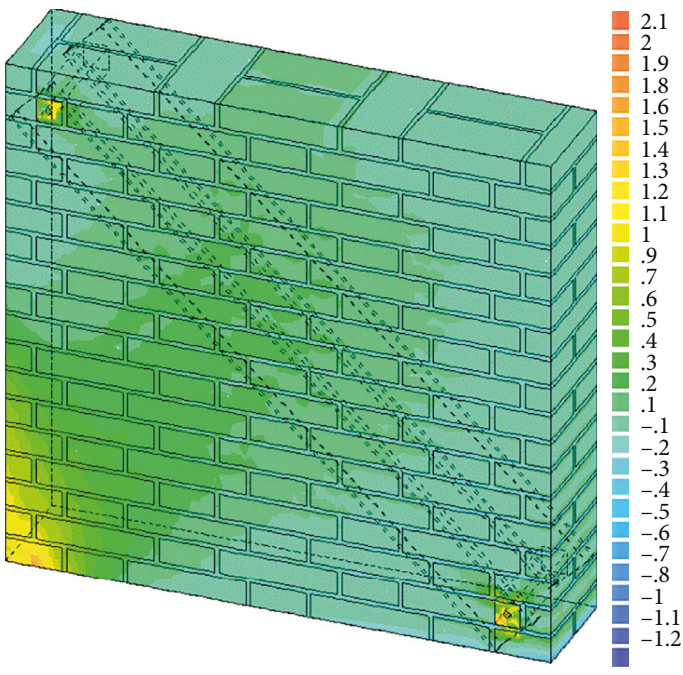

(a)

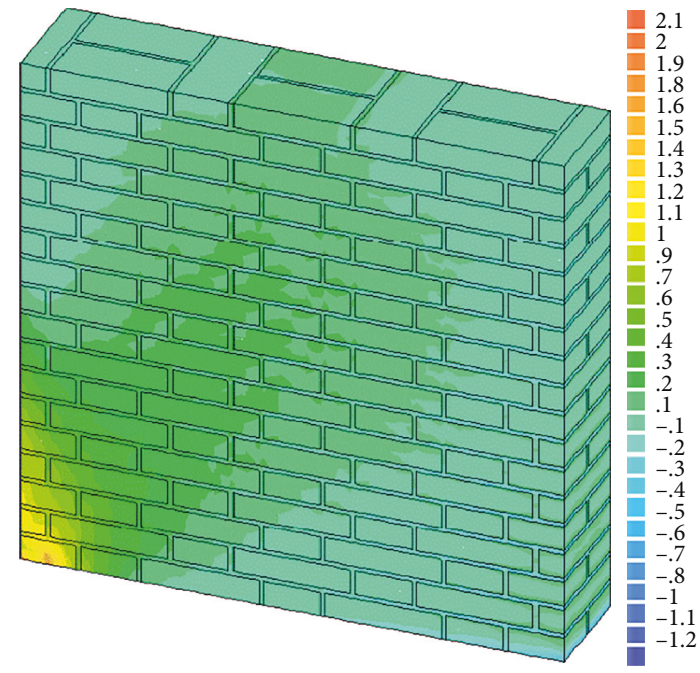

(b)

FigURE 13: Contour plots of maximum principal stress $\sigma_{1}$ in the wallette at the peak load step. (a) Peak load $=69.05$ displacement at peak load: $0.666 \mathrm{~mm}$, initial shear stiffness: $336 \mathrm{~N} / \mathrm{mm}^{2}$. (b) Peak load $=68.72$ displacement at peak load: $0.666 \mathrm{~mm}$, initial shear stiffness: $378 \mathrm{~N} / \mathrm{mm}^{2}$.

wallette. The brickwork texture was represented in consideration of the model's scale to account for material's orthotropy. The mesh density was lower than the 2D models, to get a good compromise between accuracy and computational time. We applied energy convergence criterion, with tolerance norm $10^{-3}$. A horizontal load was applied at the top short edge of the wallette in order to make the PFRP profile work as a strut; a constant vertical load of $0.6 \mathrm{~N} / \mathrm{mm}^{2}$ as in the tests was also accounted for. The analyses' output is summarized in Figures 13 and 14. The maximum load capacity and the displacements are almost the same in both cases. Figures 13(a) and 13(b) shows the contour plots of the maximum principal stress $\sigma_{1}$ in the wallette at the peak load step. In the strengthened model, cracks first appear around the connection bars (Figure 13(a)), but the stress state at failure in the wallette is similar to that of the unstrengthened condition, as well as the incipient rocking mode.
The graph in Figure 14 enlightens the stress level (i.e., ratio of acting stress to corresponding value of strength) in the wallette, steel bars and PFRP profile at increasing load rate (i.e., ratio of acting load to maximum load of the sole wallette). In opposition to the experimental and $2 \mathrm{D} \mathrm{FE}$ model results, the stress rate of the steel bars remains low, because of the greater stiffness opposed by the masonry wallette. All the results show that the tested single-bar connection system would not grant an opportune exploitation of the PFRP strut as a strengthening member.

The results of the 3D analysis (wallette with barconnected PFRP single strut) seem to contradict the previous FE simulations (wall with PFRP moment frame strengthening, Figure 1); as in the latter system the load is effectively transferred from the masonry to the frame and the mechanical performance is improved. This can be due to the combined behavior of frame members and to the 


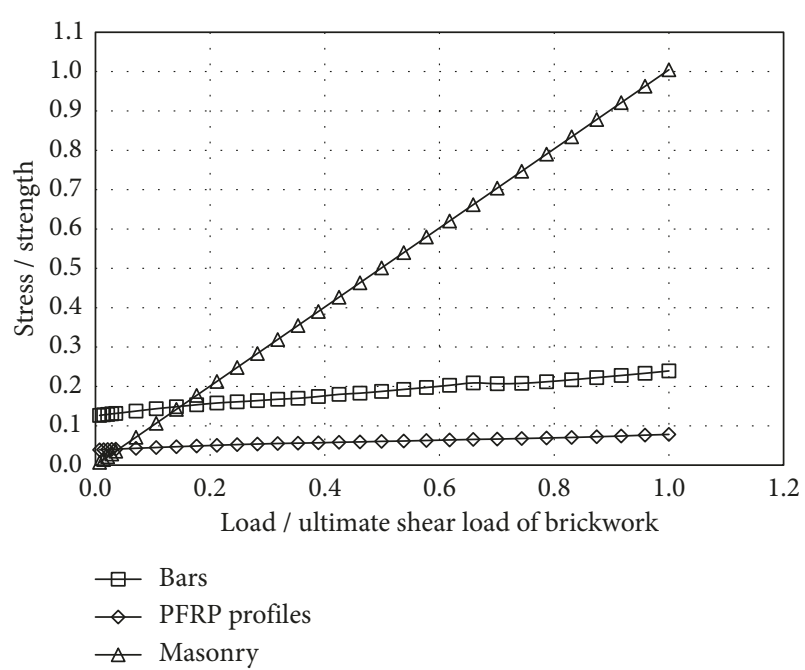

FIGURE 14: Stress rate in the masonry, bars, and GFRP profiles at increasing load, FE analysis.

assumption of very rigid connections, while the detailed 3D here presented reproduces the joint as it was in the physical model and in the 2D simulation. In both the models, the first cracks develop around the connecting bars, and the failure mode of the masonry panel without strengthening (i.e., rocking) is the same in both the previous and the present models. Thus, the increase in stiffness of the strengthening system and connections will drive the next research steps, on a $116 \times 116 \times 25$ wallette.

\section{Conclusions}

The first experimental results here reported come from small samples, reproducing one single-bolted joint of a FRP pultruded profile to masonry. The tests aimed at an insight on the elements of the joint, i.e., the steel bar, the hole in the FRP profile, the hole in the perforated masonry, and possibly the FRP plate and the epoxy adhesive bonding.

(i) The use of adhesive joint between the GFRP profile and the plate (type 1 samples) increases the elastic stiffness, but brings on a brittle collapse and lower load capacity than samples without interposed plate and adhesive (type 2). The type and role of adhesive might be worth reconsidering, for instance, in full adhesive masonry-PFRP joints, which would involve only shear transfer mechanisms. Such studies are now in progress at our laboratory.

(ii) Connection type 2 (one bar only) is less stiff but allows for higher loads and displacements than type 1. This seems promising, but the tests enlighten the predominance of bar's flexural behavior; on the other hand, in actual frame-wall assemblies, we expect a predominant shear behavior in transmission of lateral forces [27]. Thus, a more complex physical modelling of the strengthening system is necessary. This can involve bigger samples (e.g., at the scale of the 3D simulation) under shear load and a multibar connection.

(iii) Type 3 (two independent bars) shows lesser performance with stiffness similar to type 2 and maximum loads similar to type 1 ; consequently, type 3 will be discarded from the future programs of research.

(iv) The finite element simulations of the tested samples can catch the actual failure mechanism, triggered by the plastic deformation of the bar under flexural stress, which breaks the surrounding masonry. The 2D FE approach, which can also support increase in mesh density without too long computations, can thus be useful for the future research developments.

(v) The 3D models of a $116 \times 116 \times 25 \mathrm{~cm}$ masonry wallette, with and without the single PFRP strut connected with the 1-bar system, confirm the ineffectiveness of the strengthening system at a larger scale than the tested model. Although in the 3D model the bars do not yield and reach the $25 \%$ of their strength, the cracking still begins at connection zones; however, the addition of the PFRP strut gives negligible increase in ultimate shear load and does not affect the failure mode (i.e., rocking) of the wallette. Thus, the properties of PFRP profiles could not be exploited with this simple model. To this regard, the results, especially those of samples 1a-b, suggest investigating bolted connections without plates+adhesive and simple frame system instead of single struts. The exploitation rate in the GFRP elements, with respect to their axial capacity, will be paid particular attention in consideration of the risk of local buckling of compressed members.

\section{Data Availability}

The data used to support the findings of this study are available from the corresponding author upon request.

\section{Conflicts of Interest}

The authors declare that there are no conflicts of interest regarding the publication of this paper.

\section{Acknowledgments}

The authors are grateful to the technical and administrative personnel of the IUAV Laboratory of Strength of Materials (LabSCo). The research was supported by the yearly institutional research funding of the IUAV University of Venice.

\section{References}

[1] D. C. Rai and S. C. Goel, "Seismic strengthening of unreinforced masonry piers with steel elements," Earthquake Spectra, vol. 12, no. 4, pp. 845-862, 1996. 
[2] F. M. Mazzolani and M. Ivanyi, Refurbishment of Buildings and Bridges, Springer-Verlag, Wien, Austria, ISBN 3-21183690-X, 2002.

[3] University of Bath, 2015 Available from http://www. circularecology.com/embodied-energy-and-carbon-footprintdatabase.html [cited February 2015].

[4] H.-C. Wu and A. Yan, "Durability simulation of FRP bridge decks subject to weathering," Composites Part B: Engineering, vol. 51, pp. 162-168, 2013.

[5] T. Stratford, "The condition of the Aberfeldy footbridge after 20 years in service," in Proceedings of Structural Faults and Repair 2012, Edinburgh, United Kingdom, July 2012.

[6] R. Stewart, "Building on the advantages of composites in construction," Reinforced Plastics, vol. 54, no. 5, pp. 20-27, 2010.

[7] R. Sonnenschein, K. Gajdosova, and I. Holly, "FRP composites and their using in the construction of bridges," Procedia Engineering, vol. 161, pp. 477-482, 2016.

[8] L. C. Hollaway, "A review of the present and future utilisation of FRP composites in the civil infrastructure with reference to their important in-service properties," Construction and Building Materials, vol. 24, no. 12, pp. 2419-2445, 2010.

[9] M. Heshmati, R. Haghani, and M. Al-Emrani, "Environmental durability of adhesively bonded FRP/steel joints in civil engineering applications: state of the art," Composites Part B: Engineering, vol. 81, pp. 259-275, 2015.

[10] A. Zaman, S. A. Gutub, and M. A. Wafa, "A review on FRP composites applications and durability concerns in the construction sector," Journal of Reinforced Plastics and Composites, vol. 32, no. 24, pp. 1966-1988, 2013.

[11] H.-C. Wu, G. Fu, R. F. Gibson, A. Yan, K. Warnemuende, and V. Anumandla, "Durability of FRP composite bridge deck materials under freeze-thaw and low temperature conditions," Journal of Bridge Engineering, vol. 11, no. 4, pp. 443451, 2006.

[12] G. Boscato, C. Casalegno, and S. Russo, "Creep effects in pultruded FRP beams," Mechanics of Composite Materials, vol. 52, no. 1, pp. 27-42, 2016.

[13] H. Niroumand, "Fibre reinforced polymer (FRP) in civil, structure \& geotechnical engineering," in Proceedings of Second International Conference of International Institute for FRP in Construction for Asia-Pacific Region (APFIS 2009), Seoul, South Korea, December 2009.

[14] G. Boscato and S. Russo, "Free vibrations of a pultruded GFRP frame with different rotational stiffnesses of bolted joints," Mechanics of Composite Materials, vol. 48, no. 6, pp. 655-668, 2013.

[15] G. Boscato and S. Russo, "Structural performance of ironwood-FRP pedestrian bridge," in Proceedings of the Fourth International Conference on FRP Composites in Civil Engineering (CICE 2008), Zurich, Switzerland, July 2008.

[16] A. Borri and A. Giannantoni, "Reinforcement of timber floors with FRP pultruded elements," in Proceedings of Mechanics of Masonry Structures Strengthened with FRP-materials: Modeling, Testing, Design, Control, Venezia, Italy, December 2004.

[17] C. Casalegno and S. Russo, "Pushover analysis of GFRP pultruded frames," Mechanics of Composite Materials, vol. 51, no. 5, pp. 593-608, 2015.

[18] A. Cecchi, S. Russo, and F. Sciarretta, "Preliminary investigation on FRP profiles for the structural retrofit of masonry structures," Key Engineering Materials, vol. 747, pp. 77-84, 2017.

[19] S. El-Borgi, H. Smaoui, F. Casciati, K. Jerbi, and F. Kanoun, "Seismic evaluation and innovative retrofit of a historical building in Tunisia," Structural Control and Health Monitoring, vol. 12, pp. 179-195, 2004.

[20] A. Papalou, "Strengthening of masonry structures using steel frames," International Journal of Engineering and Technology, vol. 2, no. 1, pp. 50-56, 2012.

[21] D. D. Dempsey and D. W. Scott, "Wood members strengthened with mechanically fastened FRP strips," Journal of Composites for Construction, vol. 10, no. 5, pp. 392-398, 2006.

[22] W. E. Elsayed, U. A. Ebead, and K. W. Neale, "Studies on mechanically fastened fiber-reinforced polymer strengthening systems," ACI Structural Journal, vol. 106, no. 1, pp. 49-59, 2009.

[23] F. Nardone, G. P. Lignola, A. Prota, G. Manfredi, and A. Nanni, "Modeling of flexural behavior of RC beams strengthened with mechanically fastened FRP strips," Composite Structures, vol. 93, no. 8, pp. 1973-1985, 2011.

[24] E. Martinelli, A. Napoli, B. Nunziata, and R. Realfonzo, "Inverse identification of a bearing-stress-interface-slip relationship in mechanically fastened FRP laminates," Composite Structures, vol. 94, no. 8, pp. 2548-2560, 2012.

[25] C. Casalegno, S. Russo, and F. Sciarretta, "2016. Preliminary numerical analysis of a masonry panel reinforced with pultruded GFRP profiles," in Proceedings of International Conference on Civil and Building Materials (ICCBM 2016), Hongkong, Hongkong, October 2016.

[26] C. Casalegno, S. Russo, and F. Sciarretta, "Numerical analysis of a masonry panel reinforced with pultruded FRP frames: preliminary evaluation and potentiality," Mechanics of Composite Materials, vol. 54, no. 2, pp. 207-220, 2018.

[27] G. Buonocore, A. Gesualdo, M. Monaco, and M. T. Savino, "Improvement of seismic performance of unreinforced masonry buildings using steel frames," in Proceedings of the Twelfth International Conference on Computational Structures Technology, Naples, Italy, September 2014. 


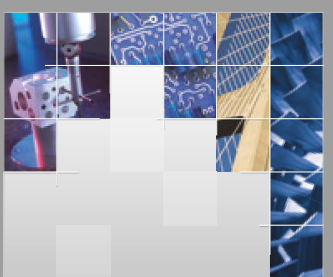

\section{Enfincering}
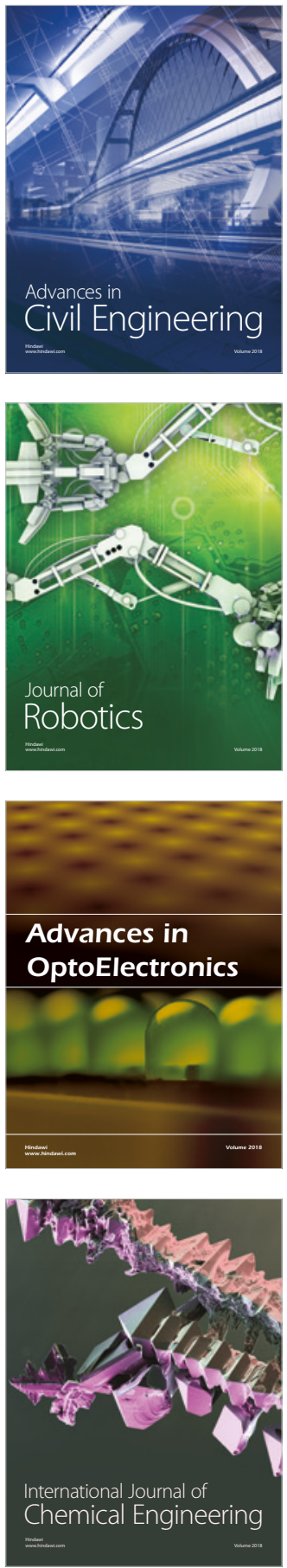

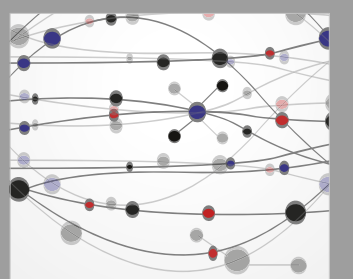

\section{Rotating \\ Machinery}

The Scientific World Journal

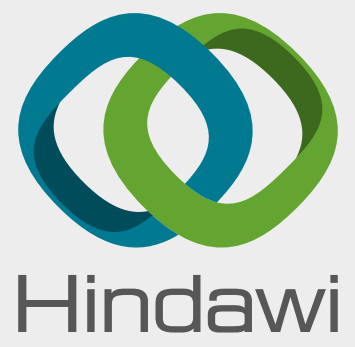

Submit your manuscripts at

www.hindawi.com
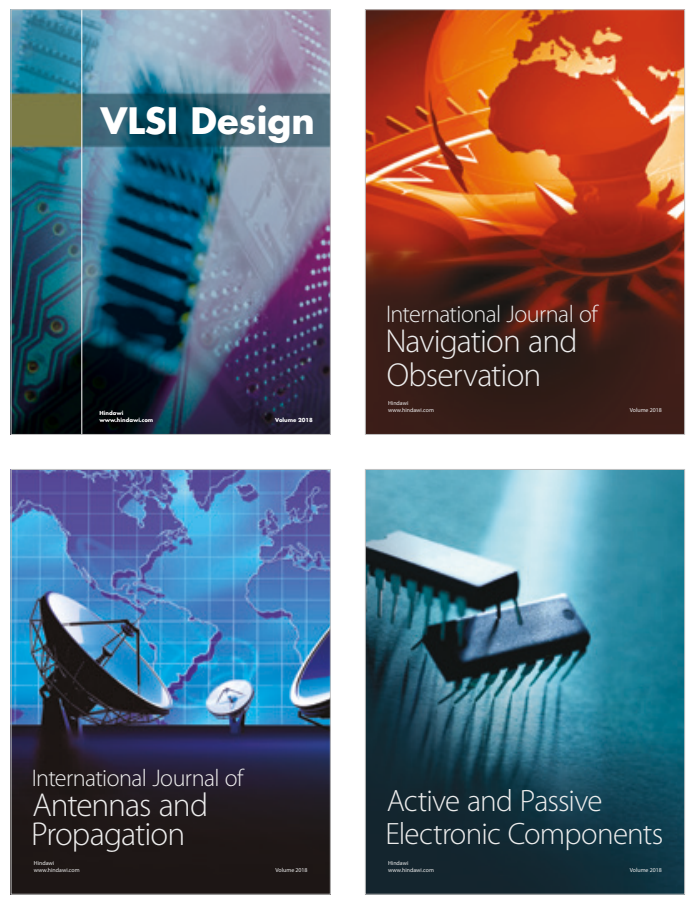
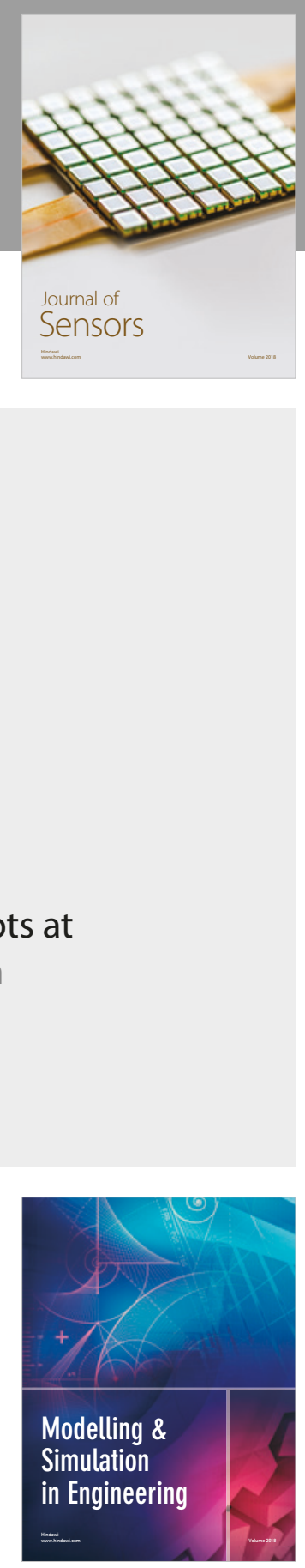

\section{Advances \\ Multimedia}
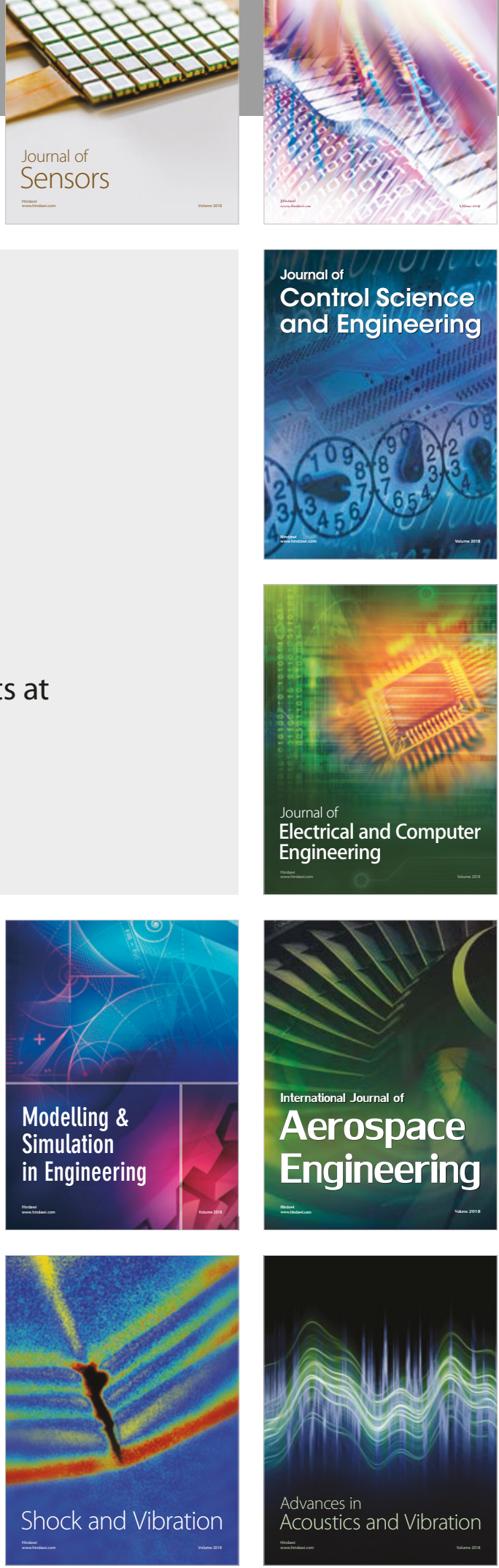